\title{
Effect of ice maturation, freezing and heat treatment on the peelability and quality of cold water shrimps (Pandalus borealis)
}

Gringer, Nina; Skytte, Jacob Lercke; Dang, Tem Thi; Orlien, Vibeke; Olsen, Karsten; SchlippèSteffensen, Kaino; Jessen, Flemming

\section{Published in:}

LWT

Link to article, DOI:

10.1016/j.Iwt.2020.110139

Publication date:

2020

Document Version

Peer reviewed version

Link back to DTU Orbit

Citation (APA):

Gringer, N., Skytte, J. L., Dang, T. T., Orlien, V., Olsen, K., Schlippè-Steffensen, K., \& Jessen, F. (2020). Effect of ice maturation, freezing and heat treatment on the peelability and quality of cold water shrimps (Pandalus borealis). LWT, 134, [110139]. https://doi.org/10.1016/j.Iwt.2020.110139

\section{General rights}

Copyright and moral rights for the publications made accessible in the public portal are retained by the authors and/or other copyright owners and it is a condition of accessing publications that users recognise and abide by the legal requirements associated with these rights.

- Users may download and print one copy of any publication from the public portal for the purpose of private study or research.

- You may not further distribute the material or use it for any profit-making activity or commercial gain

- You may freely distribute the URL identifying the publication in the public portal 
1 Effect of Ice Maturation, Freezing and Heat Treatment on the Peelability and Quality of Cold Water

2 Shrimps (Pandalus borealis)

3

4 Nina Gringer ${ }^{\mathrm{a}, *}$, Jacob Lercke Skytte ${ }^{\mathrm{a}}$, Tem Thi Dang ${ }^{\mathrm{b}}$, Vibeke Orlien ${ }^{\mathrm{b}}$, Karsten Olsen ${ }^{\mathrm{b}}$, Kaino

5 Schlippè-steffensen ${ }^{c}$ and Flemming Jessen ${ }^{\mathrm{a}}$

$6{ }^{a}$ National Food Institute, Technical University of Denmark, Søltofts Plads, Building 227, DK-2800

$7 \quad$ Kgs. Lyngby, Denmark

$8{ }^{b}$ Department of Food Science, Faculty of Science, University of Copenhagen, Rolighedsvej 26, DK-

91958 Frederiksberg C, Denmark

$10{ }^{c}$ Launis A/S, Industrivej Nord 2, DK-9982 Ålbæk, Denmark.

11

12

* Corresponding author at: National Food Institute, Technical University of Denmark, Søltofts Plads,

13 Building 227, DK-2800 Kgs. Lyngby, Denmark

14 E-mail address: ngri@food.dtu.dk (Nina Gringer). 
1

2 Worldwide shrimps are considered a delicate food. The cold water shrimp, Pandalus borealis, spends 3

up to seven years in the sea before it reaches the preferred size for consumption, valued by consumers due to its sweet taste and firm texture. In 1994 the sensory quality of shrimps were defined with a complex set of characteristics including appearance, aroma, taste and texture (Shahidi \& Botta, 1994).

These characteristics are all affected by processing and the shrimp industry has a set of choices when producing shrimps ready for sale. The shrimps can be processed fresh; i.e. after catch the fresh shrimps undergo a maturation to loosen the shell before heat treatment and (mechanical) peeling; or the shrimps can be frozen on-board or upon landing and kept frozen until processing, where the latter include thawing, appropriate maturation, heat treatment and (mechanical) peeling, unless the shrimps are sold as a frozen, untreated product. The quality characteristics of shrimp are the red colour, the sweet taste and the firm texture, hence, the challenge of the industry is to use the right processing technique resulting in red shrimps with firm texture and sweet taste.

The maturation step is a crucial step in the shrimp processing in order to obtain a high peeling yield and shrimps with intact muscle, i.e. intact tail (Dang et al., 2018b). The maturation methods used by most shrimp industries today are either submerging the frozen shrimps in a brine (with salts for up to two days) or covering the unfrozen shrimps with ice (up to seven days). The maturation weakens the connective attachment between shell and muscle, which facilitates the subsequent machine peeling. However, too long maturation induces quality loss of the peeled shrimp, leading to less red and more yellow shrimps after cooking, and loss of the amino acids responsible for the sweet taste of the final product (Høegh, 1989; Erickson, Bulgarelli, Resurreccion, Vendetti, \& Gates, 2007). Furthermore, the juiciness of cooked shrimps has been shown to decrease in shrimps during storage on ice (Erickson et al., 2007). 
24 After the maturation step, heat treatment is necessary to provide a tender and cooked shrimp product

and to inactivate bacteria i.e. Listeria monocytogene (Mejlholm, Devitt, \& Dalgaard, 2012). However, as thermal processing affects the sensory and textural characteristics of shrimp (Mizuta, Yamada, Miyagi, \& Yoshinaka, 1999; Erdogdu \& Blaban, 2000; Niamnuy, Devahastin, \& Soponronnarit, 2007; Niamnuy, Devahastin, \& Soponronnarit, 2008; Sundararajan et al., 2011), care has to be taken not to overcook the shrimps as this will compromise the quality of the final product. Quality changes due to cooking are partly caused by denaturation of proteins affecting the quality characteristics like tenderness, moisture content, juiciness and flavour (Sundararajan et al., 2011). Since texture may change dramatically during extended cooking it is considered as one of the most important quality parameters in relation to shrimp processing (Wang et al., 2018).

The aim of this work was to provide knowledge about the effects of ice maturation and freezing on the sensory quality, i.e. colour and texture (consumer perspective), as well as the peelability (industry perspective, measured by the mechanical peeling work) of ready-to-eat (matured, heat treated and peeled) cold water shrimps. In addition, two capture locations have been tested to include the natural variation in shrimps, and both uncooked and steamed shrimps were included to evaluate the interdependency of the quality and peeling work measured in the uncooked and heat treated shrimps.

\section{Materials \& Methods}

\subsection{Experimental design}

Two batches of shrimps (A and B), differing in catching time and location, have been analysed. In each batch, the shrimps were iced immediately after catch and then at day one divided into two groups: unfrozen and frozen (at $-20{ }^{\circ} \mathrm{C}$ and stored for two months before used). After frozen storage the shrimps were thawed in cold water for five min before maturation. 
47 Shrimp from both the unfrozen and frozen groups were matured on ice for one, two, three and four

days. After maturation, shrimps were subdivided into two subgroups: matured uncooked (immediately analyses of peelability and quality after maturation) and matured steamed (steamed at $100{ }^{\circ} \mathrm{C}$ for $90 \mathrm{~s}$ before analyses of peelability and quality). Figure 1 summarizes the experimental setup, and in total 1760 shrimps have been used for this study; 640 were used to test the peeling work; 560 were used for the textural quality (Texture Profile Analysis, TPA analysis); and 560 were used for the colour measurement.

\subsection{Shrimps, maturation and heat treatment}

Launis A/S provided freshly landed shrimps (max 24 hour from catch to landing) from Skagen, Denmark. Shrimps in batch A were caught from shallow waters in the northeast part of Skagerrak on $26^{\text {th }}$ of September 2016. Batch B was caught from deep waters in the northwest part of Skagerrak on $5^{\text {th }}$ of December 2016. Both batches were delivered on ice (made on tap water) to the laboratory in Kgs. Lyngby within $24 \mathrm{~h}$. Both batches were ocean-run, i.e. all sizes included (2.6-13.6 g/shrimp).

The ice maturation of shrimps was conducted in plastic containers at $2{ }^{\circ} \mathrm{C}$ by placing a layer of shrimps (approx. two $\mathrm{cm}$ ) between two thick layers of ice (approx. five $\mathrm{cm}$, made on ion-exchanged water) for up to four days. The shrimps were in direct contact with the ice. New granular ice was added daily to the shrimp-ice mixture and meltwater were allowed to drain off. The shrimps were heat treated by steaming a layer (approx. $250 \mathrm{~g}$ ) of shrimps in a stainless steel pot (28 $\mathrm{cm}$ in diameter) with boiling water (approx. six L) for $90 \mathrm{~s}$. The shrimps were placed on a horizontally stainless steel sieve (two $\mathrm{cm}$ above the water) which was custom-made to fit the pot diameter, thus allowing all shrimps to obtain the same heat level. Immediately after steaming, the shrimps were cooled in ice water for one min. to stop the cooking process and drained in a sieve for five min. before analysis. 


\subsection{Colour and texture profile analysis}

Colour and texture were evaluated on hand-peeled shrimps (shrimp meat) either immediately after ice maturation (uncooked) or after ice maturation and steaming (steamed).

Texture profile analysis (TPA) was performed using a Texture Analyser XT Plus (Stable Micro Systems Ltd., UK). A muscle sample with the length of $1.50 \mathrm{~cm}$ measured from the head end of the muscle towards the tail was isolated, kept on ice $\left(2{ }^{\circ} \mathrm{C}\right)$, placed on the platform on one side, and compressed by a P50 cylindrical probe $(50 \mathrm{~mm}$ in diameter). As all samples ( $\mathrm{n}=20$ for all sampling points in the experimental design) for the TPA test were selected with the criteria of having similar size $(0.96 \pm 0.14 \mathrm{~g} / 1.50 \mathrm{~cm})$, the samples were assumed sufficiently identical to compare the results between shrimps. Settings for TPA were: constant test speed, $1.0 \mathrm{~mm} / \mathrm{sec}$; sample deformation, 50\%; and holdtime between cycles, $10 \mathrm{sec}$. The texture analysis parameters hardness (maximum force at first compression, $\mathrm{N}$ ), resilience (upstroke energy of first compression divided by downstroke energy of first compression, \%), springiness (distance of second compression divided by distance of first compression, $\%$ ), and chewiness (product of hardness; area of second compression divided with area of first compression; and springiness, N) were calculated from the force-time curves generated by the in-built software Texture Exponent 32. Results are presented as median values.

The colour of the shrimps $(n=20$ for all sampling points in the experimental design) was assessed using the VideometerLab 2 instrument (Videometer A/S, Hørsholm, Denmark), where the CIE Lab values $\left(L^{*}=\right.$ lightness, $a^{*}=$ redness and greenness, and $b^{*}=$ yellowness and blueness $)$ were recorded at a D65 standard illuminant. Shrimps were placed in a petri dish and positioned in the Videometer for recording and the surface of the shrimp muscle was analysed by image segmentation using the in-built software. Hereafter, the three colour components for each shrimp was estimated by the average 
intensity value across all pixels covering the segmented shrimp muscle and the results are presented as the median value.

\subsection{Peelability method}

The peelability was assessed by measuring the mechanical peeling work as previously presented (Gringer et al., 2018). In brief, the first three abdominal segments of the shrimp body were carefully isolated, legs cut off and sample weighed. This part is from now on referred to as the shrimp sample, denoted SS. The SS was attached to a needle on the base plate of a Texture Analyser XT Plus (Stable Micro Systems Ltd., UK) where it could freely rotate around the needle during the peeling, thus minimizing the effect of the meat sticking to the needle. The probe of the Texture Analyser was mounted with a metallic hinge clip. The peeling was conducted by pulling the shell off (constant speed of one $\mathrm{mm} / \mathrm{sec}$ for a distance of $60 \mathrm{~mm}$ ) the muscle after attaching the hinge clip to the shell on one side of the sample. The total work (area under the force-distance curve, $\mathrm{N} \cdot \mathrm{mm}=\mathrm{mJ}$ ) used to peel the shrimp (referred to as peeling work) was calculated for each shrimp which were peeled satisfactory (no shell parts left on the meat) and normalized by dividing with the mass of the sample (work/mass of SS). For each sampling point in the experimental design, 20-30 shrimps were peeled $(n=30$ for B and B-f (Figure 1), n=20 for all other) of which 55-100 \% were peeled satisfactory. The results are presented as the median values.

\subsection{Data analysis}

The measurement data were grouped according to the sample treatment (the experimental design) resulting in 28 groups (seven sampling groups measures for four days). Within each group, the mean, the standard deviation and the median were calculated, and the number of values recorded. The group 
medians were used in Figures 2-4 to illustrate the dependence of the various quality and peeling

117 parameters on maturation time. The mean, standard deviation and number of values were used for statistical analysis of peelability (two-way ANOVA, maturation time and treatment/batch, with 119 Tukey's post-test, using $p<0.05$ as level of significance), and of day 1 texture and colour data (one-way ANOVA with Holm-Sidak's multiple comparison test between treatments). Calculations were made by use of the program Prism 6 from GraphPad Software, San Diego, USA.

3. Results and discussion

3.1. Quality changes in steamed shrimps due to ice maturation

The quality parameters, texture and colour of the final product (the steamed and peeled shrimps), were followed as a function of ice maturation time of the uncooked shrimps for up to four days in order to study the influence of the maturation process on quality. The shrimps were matured on ice as uncooked shrimps (+/- frozen storage) and steamed and peeled (thus ready-to-eat) before analysis of the texture and the colour. In Table 1 the textural parameters hardness, resilience, springiness and chewiness are shown for all the analysed groups of steamed shrimps after maturation for up to four days. No systematic differences were found neither between the steamed groups (A-fs, B-s and B-fs) nor between maturation times, except from springiness that seemed to change systematically for the three groups during the maturation, i.e. the springiness was increasing with time (from $60-65 \%$ to $64-80 \%$ ), thus the longer period of ice maturation the springier the steamed shrimps got (Figure 2). Studies of the instrumental textural quality in heat treated shrimp after different periods of ice maturation are sparse, but some studies have been performed using sensory analysis for textural evaluation. Based on a trained sensory panel, Thimmappa and co-workers (2019) reported that the prime textual quality of heat treated shrimps was maintained for four days in ice, and reached to the lower margin of 
acceptability on the 7th day (measured on a ten-point scale from excellent to not acceptable)

140 (Thimmappa, Manjunatha, Prabhu, \& Elavarasan, 2019). Erickson et al. (2007) also considered the

141 textural changes in cooked warm water shrimp noted upon ice maturation for up to ten days as 142 detrimental to the quality, i.e. shrimps that had been on ice for long time were firmer and less juicy than 143 the fresh shrimps.

144 The effects of ice maturation on the colour of the steamed shrimps are shown in Figure 3. Regardless of batch $\mathrm{A}$ or $\mathrm{B}$ and with/without frozen storage, all steamed shrimps showed a decrease in the $L^{*}$ component (whiteness) and an increase in the $b^{*}$ component (yellowness) with increased time of maturation. The $a^{*}$ value (redness) of unfrozen, steamed shrimps (B-s) constantly decreased over maturation time whereas that of frozen, steamed shrimps (B-fs) remained almost unchanged. Although the redness of unfrozen, steamed shrimps decreased, its value was still higher than frozen-steamed shrimps at the end of maturation (4 days). The decrease in redness could be attributed to the decrease in astaxanthin content that is predominantly present in epidermis of shrimp (Nègre-Sadargues et al., 1993). Thus the steamed ready-to-eat shrimps appeared less white and more yellow after ice maturation of unfrozen shrimps for four days compared to one day. Even though the redness of the frozen, thawed and steamed shrimps did not change during the ice maturation, the level was still lower than in the unfrozen shrimps and combined with the found decrease in whiteness and increase in yellowness this changed the overall appearance of the shrimps in a less attractive direction (Høegh, 1989). Flores \& Crawford (1973) found that the level of total carotenoid (astaxanthin and astacin) decreased in $P$. jordani during the first two days of ice maturation of unfrozen shrimps, which is in accordance with the 159 decrease in $a^{*}$ value of the unfrozen batch B observed in Figure 3, panel II. In addition, this loss of red colour during ice maturation is an empirical observation in the industry which is an unneglectable focus point in optimizing the process (Launis $\mathrm{A} / \mathrm{S}$, personal communication). 
3.2. Effect of freezing on the quality in steamed shrimps

164 Freezing of the shrimps before ice maturation affect the quality of the steamed shrimps (A-fs and B-fs) 165 differently compared to the unfrozen, steamed shrimps (B-s).

166 From Table 1 it is seen that frozen storage at $-20^{\circ} \mathrm{C}$ for two months prior to maturation on ice, for 167 three to four days, and a subsequent steaming and peeling results in more springy shrimps (A-fs and B168 fs) compared to the shrimps which have been matured, steamed and peeled immediately after landing (B-s). Furthermore, the frozen storage not only resulted in more springy shrimps (A-fs and B-fs) than the unfrozen shrimps (B-s) but also in a more pronounced increase in springiness over time (Figure 2). This increase in springiness of the frozen stored shrimps might be due to freezing-induced denaturation of shrimp protein, caused by the formation of larger ice crystals, which have been reported to take place in uncooked shrimps during freezing (Lopkulkiaert, Prapatsornwattana, \& Rungsardthong, 2009). In contrast, Nip \& Moy (1981) did not report notable differences in texture of unfrozen and frozen $(-18$ ${ }^{\circ} \mathrm{C}$, one month) warm water shrimps. In addition, Figure 3 reveal that freezing not only affected the final texture but also the colour of the ready-to-eat shrimps. The shrimps that had been frozen for two months and then subsequently steamed (A-fs and B-fs) were less red and more yellow than the unfrozen steamed shrimps (B-s), i.e. the $a^{*}$ components were lower and the $b^{*}$ components higher at day one after freezing compared to no freezing (Figure 3). Thus, the frozen storage of uncooked shrimps for two months had negatively affected the colour of the shrimps, reducing the wanted red colour and increasing the very unwanted yellow colour. However, while the redness of frozen shrimps (A-fs and B-fs) remained unchanged over the four-day maturation period the redness of unfrozen shrimps (B-s) constantly decreased to the same redness level of frozen shrimps at the end of maturation. In contrast, the yellowness of the unfrozen 
shrimps (B-s) not only started at a lower level at day one, but also maintained at the same level throughout the maturation time, whereas the frozen shrimps (A-fs and B-fs) got more and more yellow during the maturation time. In this respect it could thus be an advantage for the shrimps industry to avoid a frozen storage of the shrimp in order to avoid unwanted colour changes.

The peelability of shrimps is of outmost importance for shrimp manufacturers due to the direct relationship to the peeling yield and the efficiency of the peeling process (Gringer et al., 2018; Dang et al., 2018a). As a rule of thumb, $1 \%$ change in peeling yield corresponds to a $10 \%$ change in the contribution margin (Høegh, 1989) obviously emphasizing the importance of improving the maturation process for the shrimp industry.

In the present study, peelability was assessed by a quantitative measurement of the mechanical work needed to separate the shell from the muscle, referred to as the peeling work. The peeling work for both uncooked and steamed shrimps as a function of time of ice maturation is shown in Figure 4. According to the industry, the shrimps are almost impossible to peel on the peeling machines before four, sometimes even more, days on ice (Launis A/S, personal communication). Machine peeling of shrimps, which have not been matured properly, will result in lower peeling yield and thus a loss in revenue. The fact that ice maturation positively affect the peelability of shrimps is in accordance with earlier studies (Gringer et al., 2018; Høegh, 1989). In the present study it was found that for the steamed shrimps the peeling work throughout the four days of ice maturation did not change significantly (Figure 4; the three solid lines, A-fs, B-s and B-fs) leading to the conclusion that ice maturation for more than one day was not needed to improve the peeling work. This is in contrast to the industrial practice where 207 maturation time for up to seven days are needed to ensure proper peeling (Launis A/S, personal 
communication). Thus, the method used here to evaluate the peeling work might not be applicable for imitating the actual peeling on the automatic peeling machines.

Two batches ( $\mathrm{A}$ and $\mathrm{B}$ ) were tested to explore the relationship between catching place and maturation effect on shell-loosening. The peeling work of the two batches did not differ significantly (Figure 4) and neither did the textural characteristics. However, the colour of the two batches analysed were somewhat different, i.e. batch B appeared redder and less white than batch A (Figure 3).

\subsection{Interdependence of quality and peeling work of steamed and uncooked shrimps}

A second goal in this study was to evaluate if there exist interdependency between attributes measured in uncooked and in steamed shrimps. In order to assess this, all the measurements conducted in the steamed shrimps were likewise conducted in the uncooked shrimps after the same treatments (Figure $1)$.

The texture did change during the ice maturation and during the subsequent heat treatment, and while springiness increased during maturation time in the steamed shrimps (Figure 2, A-fs, B-s and B-fs), it decreased in the uncooked shrimps (Table 1, A, A-f, B and B-f). Furthermore, after one day of ice maturation the steamed and uncooked shrimps had the same level of springiness, while both hardness, resilience and chewiness were at a higher level in the steamed shrimps compared to the uncooked shrimps, thus steaming increased these three textural parameters (Table 1). These findings are in accordance with the results presented by Erdogdu \& Blaban (2000) and Xu et al. (2016) who found that heat treatment affected the texture of shrimp meat by increasing hardness, springiness and chewiness compare to that of raw shrimps. Mizuta, Yamada, Miyagi \& Yoshinaka (1999) have also reported an enhanced firmness in shrimp meat after heat treatment and these textural changes in shrimps upon 
boiling is highly probable caused by denaturation of proteins following aggregation (Niamnuy et al., 2007).

Steaming likewise affected the colour, with the most pronounced difference in the $L^{*}$ component which were increased from a range of 66-71 in the uncooked shrimps (A, A-f, B and B-f in Table 2) after one day on ice to a range of 78-82 in the steamed shrimps (A-fs, B-s and B-fs in Table 2 and Figure 3). Although the $L^{*}$ component decreased with maturation time for the steamed shrimps, the four-day matured steamed shrimp were more white than the four-day matured uncooked shrimps. This increase in whiteness upon heat treatment (boiling in water) was also reported by Niamnuy et al. (2007). Additionally, the present study found that freezing the shrimps prior to maturation resulted in a decrease in the $L^{*}$ component during maturation, whereas the unfrozen and uncooked shrimps increased slightly in lightness during maturation and the unfrozen and steamed shrimps barely changed the lightness throughout the maturation time (Table 2). This finding is in accordance with Ma, Zhang, Deng, \& Xie (2015), who reported that the shrimps became less white during six weeks of frozen storage $\left(-18^{\circ} \mathrm{C}\right)$. In contrast, Sundararajan et al. (2011) observed an increase in the $L^{*}$ component during frozen storage at $-21{ }^{\circ} \mathrm{C}$ of raw and peeled shrimps for the first $2-4$ weeks, but then the $L^{*}$ component decreased, explained as resulting from degradation of astaxanthin and lipid oxidation. In a study by $\mathrm{Xu}$ et al. (2016), heat treatment of freshly landed shrimps was shown to increase all colour components $\left(L^{*}, a^{*}\right.$ and $\left.b^{*}\right)$ compared to uncooked shrimps. Thus, the redness of shrimps was expected to increase during heat treatment due to release of astaxanthin from the carotenoproteins upon heat-induced denaturation of these proteins (Muriana, Ruiz-Gutierrez, Gallardo-Guerrero, \& MinguezMosquera, 1993). Yet, loss of red colour during ice maturation is an empirical observation in the industry (Launis A/S, personal communication) for which reason the red colour was expected to faint with maturation time. However, no effect of ice maturation on the $a^{*}$ component was observed in 
neither uncooked nor steamed shrimps in the present work and the level of redness were not higher in the steamed shrimps compared to the uncooked shrimps (Table 2).

The evaluation of the uncooked shrimps further underlined the negative effect of freezing on yellowness, as all four groups of frozen shrimps (A-f, A-fs, B-f and B-fs) showed increasing levels of the $b^{*}$ component during maturation time, whereas the three unfrozen groups (A, B and B-s) remained at the level of yellowness from one day on ice throughout the four days of ice maturation (Table 2). In contrast to the results obtained for the $a^{*}$ and $b^{*}$ components in the present study, Okpala, Choo, \&

Dykes (2014) found that colour intensity (chroma, $\left.\left(a_{*}^{2}+b_{*}^{2}\right)^{1 / 2}\right)$, during ice maturation of shrimps, decreased slightly after one day on ice followed by a stable intensity up to day eight and then a significant increase at day 12 . An unchanged chroma value reflects no or equal change in $a^{*}$ and $b^{*}$ giving same perceived intensity or saturation of the colour, while a change in the value is a result of different effects on either $a^{*}$ or $b^{*}$. In the present study the colour intensity increased during ice maturation as a consequence of the increasing yellowness. However, Okpala et al. (2014) did not report the specific $a^{*}$ and $b^{*}$ values, but the observed decrease in chroma must reflect a decrease in at least one of these components.

It was expected that the four-day matured shrimps would be easier to peel after steaming compared to a short maturation time and compared to uncooked shrimps. However, as shown in Figure 4, the peeling work was different only on day one, i.e. the uncooked shrimps demanded more work to peel the shrimps compared to the steamed shrimps. In a previous study we showed that the peeling work 272 decreased significantly from day zero to day one (Gringer et al., 2018) and thus it would be expected that the peeling work in the present study would have been even higher at day zero than the values found at day one. This reduction in peeling work demonstrated the loosening of the shell-muscle 
microorganisms during the post-mortem storage and therefore accountable for enhancing the shell

277 removal (Crawford, 1980). However, after a significant $(p<0.05)$ decrease in peeling work in the uncooked shrimps (Figure 4, A, A-f, B and B-f) from day one to day two on ice, the peeling work was almost identical for all the seven combinations of groups. Furthermore, the peeling work stayed at a steady level throughout the rest of the maturation period, indicating that three and four days on ice did not improve the peelability. However, the steaming process promoted the shell loosening slightly, since the peeling work for the three steamed groups of shrimp were lower than the corresponding peeling work for the uncooked groups of shrimps (Figure 4).

\section{Conclusion}

The present findings on the shrimp quality parameters, changing during maturation and due to freezing and steaming, were overall in accordance with industrial observations, except for the expected reduction in red colour during maturation, which could not be documented in the present work. Additionally, no impact of maturation and freezing on peelability was found, and this is not in compliance with the industrial experience. This revealed that the applied method measuring the peeling work for evaluating the peelability was not measuring parameters representing what is actually happening on the automatic peeling machines in the industry. Although, the peeling work was a measure of the strength of properties such as specific bindings between shell and muscle of the overall shell-muscle-attachment, those bindings were evidently not the same as the shell-muscle-attachments or shell properties that are central for the actual peelability of the shrimps on the industrial peeling machines. Further studies of the structures and attachments that are important for the industrial peelability is therefore important in order to establish lab-scale measurements to use in optimizing shrimp production. 
5. Acknowledgements

302 The authors are thankful to Green Development and Demonstration Program (GUDP Denmark), The

Danish Agrifish Agency, the Ministry of Food, Agriculture and Fisheries for financial support to the project "Sustainable technologies for the optimization of shrimp production" (Grant no. 34009-140870). We thank bachelor student Simone Alpiger and lab technician Yuka Omura Lund for helping with the comprehensive lab work. A special thanks to Associate Professor Bo Munk Jørgensen for helping with the data treatment. Furthermore, Launis A/S are gratefully thanked for their cooperation and supply of raw material.

\section{References}

Crawford, D.L. (1980). Meat yield and shell removal functions of shrimp processing. Special Report 597. Oregon State University Extension Marine Advisory Program. Land Grant/ Sea Grant Cooperative.

Dang, T.T., Gringer, N., Jessen, F., Olsen, K., Bøknæs, N., Nielsen, P.L., \& Orlien, V. (2018a). Enzyme-assisted peeling of cold water shrimps (Pandalus Borealis). Innovative Food Science \& Emerging Technologies, 47, 127-135.

Dang, T.T., Gringer, N., Jessen, F., Olsen, K., Bøknæs, N., Nielsen, P.L., \& Orlien, V. (2018b). Emerging and potential technologies for facilitating shrimp peeling: A review. Innovative Food Science and Emerging Technologies, 45, 228-240.

Erdogdu, F., \& Balaban, M.O. (2000). Thermal Processing Effects on the Textural Attributes of 321 Previously Frozen Shrimp. Journal of Aquatic Food Product Technology, 9, 61-84. 
322 Erickson, M.C., Bulgarelli, M.A., Resurreccion, A.V.A., Vendetti, R.A, \& Gates, K.A. (2007). Sensory

323 differentiation of shrimps using a trained descriptive analysis panel. LWT Food Science and 324 Technology, 40, 1774-1783.

325 Flores, S.C., \& Crawford, D.L. (1973). Postmortem quality changes in iced pacific shrimp (Pandalus 326 jordani). Journal of Food Science, 38, 575-579.

327 Gringer, N., Dang, T.T., Orlien, V., Olsen, K., Bøknæs, N., \& Jessen, F. (2018). A quantitative method 328 to measure and evaluate the peelability of shrimps (Pandalus borealis). LWT - Food Science and 329 Technology, 94, 20-24.

330 Høegh, L. (1989). Kvalitetsindex for rejer. PhD thesis.

331 Lopkulkiaert, W., Prapatsornwattana, K., \& Rungsardthong, V. (2009). Effects of sodium bicarbonate 332 containing traces of citric acid in combination with sodium chloride on yield and some properties of 333 white shrimp (Penaeus vannamei) frozen by shelf freezing, air-blast and cryogenic freezing. $L W T$ 334 Food Science and Technology, 42, 768-776.

335 Ma, L-K., Zhang, B., Deng, S-G., \& Xie, C. (2015). Comparison of the cryoprotective effects of 336 trehalose, alginate, and its oligosaccharides on peeled shrimp (Litopenaeus vannamei) during 337 frozen storage. Journal of Food Science, 80, C540-C546.

338 Mejlholm, O., Devitt, T.D., \& Dalgaard, P. (2012). Effect of brine margination on survival and growth 339 of spoilage and pathogenic bacteria during processing and subsequent storage of ready-to-eat 340 shrimp (Pandalus borealis). International Journal of Food Microbiology, 175, 16-27.

341 Mizuta, S., Yamada, Y., Miyagi, T., \& Yoshinaka, R. (1999). Histological Changes in Collagen 342 Related to Textural Development of Prawn Meat During Heat Processing. Journal of Food Science, 343 64, 991-995. 
344 Muriana, F.J.G., Ruiz-Gutierrez, V., Gallardo-Guerrero, M.L., \& Minguez-Mosquera M.I. (1993). A 345 study of the lipids and carotenoprotein in the Prawn, Penaeus japonicas. Journal of Biochemistry, $346 \quad 114,223-229$.

347 Nègre-Sadargues, G., Castillo, R., Petit, H., Sancé, S., Martinez, R.G., Milicua, J.C.G., Choubert, G. 348 and Trilles, J.P. (1993). Utilization of synthetic carotenoids by the prawn Penaeus japonicas reared 349 under laboratory conditions. Aquaculture, 110, 151-159

350 Niamnuy, C., Devahastin, S., \& Soponronnarit, S. (2007). Quality Changes of Shrimp during Boiling in 351 Salt Solution. Journal of Food Science, 72, S289-S297.

352 Niamnuy, C., Devahastin, S., \& Soponronnarit, S. (2008). Changes in protein composition and their 353 effects on physical changes of shrimp during boiling in salt solution, Food Chemistry, 108, 165$354 \quad 175$.

355

Nip, W. K., \& Moy, J. H. (1981). Effect of thawing and subsequent chilling on the quality of prawn, 357 Macrobrachium rosenbergii. Journal of Food Processing and Preservation, 5, 207-213.

Okpala, C.O.R, Choo, W.S., \& Dykes, G.A. (2014), Quality and shelf life assessment of pacific white shrimp (Litopenaeus vannamei) freshly harvested and stored on ice. LWT - Food Science and Technology, 55, 110-116.

Shahidi, A.K., \& Botta, R. (1994). "Seafood: Chemistry, processing, Technology, and Quality". New 362 Sundararajan, S., Prudente, A., Bankston, J.D., King, J.M., Wilson, P., \& Sathivel, S. (2011). 363 Evaluation of green tea extract as a glazing material for shrimp frozen by cryogenic freezing. 364 Journal of Food Science, 76, E511-E518. 
365 Thimmappa, M.H., Manjunatha Reddy, A., Prabhu, R.M., \& Elavarasan, K. (2019). Quality changes in 366 deep-sea shrimp (Aristeus alcocki) during ice storage: biochemical and organoleptic changes. 367 Agricultural Research, 8, 497-504.

368 Wang, J., Tang, J., Rasco, B., Sablani, S.S., Ovissipour, M., \& Qu, Z. (2018). Kinetics of quality 369 changes of shrimp (Litopenaeus setiferus) during pasteurization. Food and Bioprocess Technology, $370 \quad 11,1027-1038$.

371 Xu, Y., Chen, Y., Cao, Y., Huang, W., Zhang, S., Xia, W., \& Jiang, Q. (2016). Effect of Steam 372 Cooking on Textural Properties and Taste Compounds of Shrimp (Metapenaeus ensis). Food $373 \quad$ Science and Technology Research, 22, 75-81. 
1 Table 1: Minimum (min.), median and maximum (max.) values of the TPA parameters springiness,

2 hardness, resilience and chewiness on all seven groups of shrimps after maturation of uncooked

3 shrimps for one-four days on ice.

\begin{tabular}{|c|c|c|c|c|c|c|c|c|c|c|c|c|c|}
\hline & & \multicolumn{3}{|c|}{ Day 1} & \multicolumn{3}{|c|}{ Day 2} & \multicolumn{3}{|c|}{ Day 3} & \multicolumn{3}{|c|}{ Day4 } \\
\hline & & Min. & Median & Max. & Min. & Median & Max. & Min. & Median & Max. & Min. & Median & Max. \\
\hline \multirow{7}{*}{ 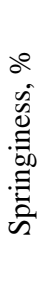 } & A & 48.5 & $62.7^{x}$ & 92.9 & 59.3 & 67.0 & 75.3 & 49.1 & 59.7 & 100.9 & 44.2 & 62.6 & 80.6 \\
\hline & A-f & 49.4 & $64.5^{x}$ & 94.8 & 47.5 & 56.7 & 95.3 & 41.3 & 50.6 & 84.1 & 42.4 & 49.8 & 92.8 \\
\hline & A-fs & 60.3 & $64.8^{x}$ & 92.8 & 59.3 & 67.0 & 75.3 & 63.5 & 71.4 & 76.3 & 61.3 & 70.3 & 78.6 \\
\hline & B & 52.5 & $74.4^{\mathrm{h}}$ & 94.6 & 56.6 & 66.6 & 92.8 & 47.7 & 57.4 & 87.5 & 45.1 & 61.4 & 95.5 \\
\hline & B-s & 55.0 & $60.1^{\mathrm{i}}$ & 79.6 & 54.2 & 63.2 & 82.0 & 48.6 & 64.3 & 73.8 & 54.5 & 63.5 & 86.3 \\
\hline & $B-f$ & 51.7 & $62.6^{\mathrm{h}, \mathrm{i}}$ & 94.3 & 52.3 & 61.6 & 96.1 & 40.4 & 51.2 & 79.7 & 43.7 & 67.7 & 87.9 \\
\hline & B-fs & 49.7 & $63.2^{\mathrm{i}}$ & 74.8 & 61.6 & 70.0 & 87.0 & 60.2 & 75.6 & 94.3 & 70.0 & 79.7 & 99.9 \\
\hline \multirow{7}{*}{ 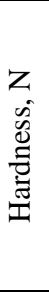 } & A & 3.0 & $4.1^{x}$ & 6.1 & 3.4 & 5.9 & 8.4 & 2.5 & 4.2 & 5.6 & 2.0 & 4.2 & 5.8 \\
\hline & A-f & 2.9 & $4.5^{\mathrm{x}}$ & 6.8 & 2.2 & 5.6 & 6.9 & 2.6 & 5.4 & 8.0 & 2.7 & 5.8 & 8.6 \\
\hline & A-fs & 4.5 & $7.4^{y}$ & 10.1 & 3.4 & 5.9 & 8.4 & 4.7 & 6.2 & 8.7 & 5.3 & 7.3 & 8.9 \\
\hline & $\mathrm{B}$ & 3.1 & $5.1^{\mathrm{h}}$ & 6.5 & 3.3 & 4.8 & 6.3 & 3.5 & 4.3 & 6.1 & 3.1 & 4.3 & 5.7 \\
\hline & B-s & 4.1 & $6.1^{\mathrm{h}}$ & 7.4 & 4.4 & 6.9 & 10.2 & 3.4 & 5.4 & 8.8 & 4.1 & 5.6 & 8.4 \\
\hline & B-f & 1.5 & $5.1^{\mathrm{h}}$ & 7.1 & 4.1 & 5.5 & 8.1 & 3.4 & 4.9 & 6.8 & 2.0 & 4.2 & 6.2 \\
\hline & B-fs & 3.0 & $5.7^{\mathrm{h}}$ & 8.6 & 4.1 & 7.3 & 9.5 & 4.5 & 6.7 & 8.2 & 3.9 & 6.3 & 7.7 \\
\hline \multirow{7}{*}{ 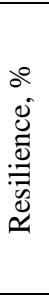 } & A & 20.3 & $23.6^{x}$ & 34.3 & 19.9 & 35.8 & 43.8 & 19.2 & 24.1 & 30.1 & 17.2 & 21.5 & 31.7 \\
\hline & A-f & 12.5 & $25.8^{x}$ & 32.7 & 21.7 & 28.4 & 39.9 & 24.1 & 30.8 & 41.1 & 23.2 & 30.0 & 39.8 \\
\hline & A-fs & 27.9 & $34.1^{\mathrm{y}}$ & 40.3 & 19.9 & 35.8 & 43.8 & 24.4 & 30.2 & 38.6 & 20.8 & 28.2 & 37.2 \\
\hline & B & 24.1 & $30.4^{\mathrm{h}}$ & 36.4 & 18.4 & 25.3 & 34.3 & 18.1 & 25.2 & 33.5 & 20.6 & 24.2 & 31.2 \\
\hline & B-s & 26.4 & $33.9^{\mathrm{i}}$ & 41.5 & 24.3 & 35.9 & 40.0 & 27.0 & 31.7 & 39.9 & 23.6 & 32.8 & 38.8 \\
\hline & B-f & 24.4 & $28.4^{\mathrm{h}}$ & 36.9 & 23.4 & 27.1 & 38.3 & 23.6 & 27.1 & 34.8 & 26.9 & 35.8 & 39.7 \\
\hline & B-fs & 25.4 & $34.3^{i}$ & 38.2 & 29.6 & 36.8 & 42.3 & 25.1 & 34.0 & 38.8 & 31.2 & 39.6 & 48.3 \\
\hline \multirow{7}{*}{ 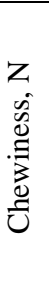 } & A & 0.7 & $1.1^{\mathrm{x}}$ & 1.4 & 1.1 & 2.4 & 3.7 & 0.6 & 1.0 & 2.2 & 0.5 & 0.8 & 1.6 \\
\hline & A-f & 0.4 & $1.3^{\mathrm{x}}$ & 2.0 & 0.8 & 1.4 & 2.2 & 0.9 & 1.2 & 2.5 & 0.8 & 1.4 & 2.3 \\
\hline & A-fs & 1.7 & $2.9^{\mathrm{y}}$ & 6.3 & 1.1 & 2.4 & 3.7 & 1.7 & 2.5 & 4.1 & 1.8 & 2.6 & 3.9 \\
\hline & B & 1.3 & $1.6^{\mathrm{h}}$ & 2.6 & 0.7 & 1.4 & 2.0 & 0.7 & 1.0 & 1.6 & 0.7 & 1.0 & 2.0 \\
\hline & B-s & 1.4 & $2.0^{\mathrm{i}}$ & 3.3 & 1.3 & 2.9 & 4.1 & 1.1 & 2.0 & 3.5 & 1.2 & 2.1 & 3.2 \\
\hline & B-f & 0.8 & $1.4^{\mathrm{h}}$ & 2.4 & 1.0 & 1.5 & 2.5 & 0.7 & 1.2 & 1.5 & 0.7 & 1.5 & 2.2 \\
\hline & B-fs & 0.8 & $2.5^{\mathrm{i}}$ & 3.9 & 1.7 & 3.2 & 5.7 & 1.5 & 3.0 & 4.0 & 2.0 & 3.4 & 4.6 \\
\hline
\end{tabular}

$4 \mathrm{n}=20$ for all measurements.

5 Values for day 1 marked with the same letter (within code A (x, y) or B (h, i)) are not significantly 6 different. 
7 Table 2: Minimum (min.), median and maximum (max.) values of the colour parameters $L^{*}, a^{*}$ and $b^{*}$

8 on all seven groups of shrimps after maturation of uncooked shrimps for one-four days on ice.

\begin{tabular}{|c|c|c|c|c|c|c|c|c|c|c|c|c|c|}
\hline & & \multicolumn{3}{|c|}{ Day 1} & \multicolumn{3}{|c|}{ Day 2} & \multicolumn{3}{|c|}{ Day 3} & \multicolumn{3}{|c|}{ Day4 } \\
\hline & & Min. & Median & Max. & Min. & Median & Max. & Min. & Median & Max. & Min. & Median & Max. \\
\hline \multirow{7}{*}{ 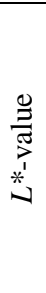 } & $\mathrm{A}$ & 67.7 & $69.2^{x}$ & 72.3 & 67.6 & 70.2 & 72.6 & 69.2 & 72.9 & 74.7 & 71.3 & 73.7 & 77.0 \\
\hline & A-f & 65.3 & $71.2^{\mathrm{y}}$ & 73.4 & 67.0 & 69.7 & 73.9 & 66.6 & 69.4 & 71.8 & 65.5 & 68.0 & 71.5 \\
\hline & A-fs & 79.3 & $81.7^{\mathrm{z}}$ & 83.2 & 76.5 & 79.9 & 81.5 & 77.3 & 78.3 & 80.2 & 73.5 & 76.9 & 78.7 \\
\hline & B & 62.3 & $66.5^{\mathrm{h}}$ & 68.7 & 62.3 & 65.8 & 69.9 & 63.7 & 67.6 & 70.7 & 64.5 & 67.9 & 72.3 \\
\hline & B-s & 73.6 & $78.6^{\mathrm{i}}$ & 81.4 & 75.9 & 79.2 & 83.0 & 75.5 & 78.2 & 82.3 & 74.7 & 77.7 & 79.3 \\
\hline & $B-f$ & 64.0 & $67.4^{\mathrm{h}}$ & 72.0 & 65.0 & 68.6 & 72.7 & 57.4 & 66.8 & 69.4 & 59.8 & 66.7 & 69.8 \\
\hline & B-fs & 75.6 & $78.1^{\mathrm{i}}$ & 81.4 & 74.7 & 78.4 & 81.4 & 72.3 & 75.6 & 77.8 & 72.3 & 75.7 & 77.5 \\
\hline \multirow{7}{*}{ 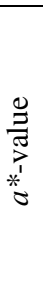 } & A & 6.5 & $7.3^{x}$ & 9.0 & 5.8 & 7.8 & 11.0 & 6.6 & 8.6 & 10.0 & 5.3 & 7.0 & 8.4 \\
\hline & A-f & 4.6 & $6.5^{\mathrm{y}}$ & 8.0 & 4.0 & 6.4 & 8.5 & 5.0 & 6.3 & 10.1 & 4.2 & 5.7 & 7.7 \\
\hline & A-fs & 5.4 & $7.0^{x}$ & 11.5 & 4.8 & 7.0 & 9.8 & 4.7 & 6.9 & 9.3 & 5.3 & 8.0 & 10.4 \\
\hline & B & 5.9 & $8.5^{\mathrm{h}}$ & 12.0 & 7.3 & 9.0 & 11.7 & 6.6 & 8.8 & 10.3 & 7.5 & 9.2 & 11.9 \\
\hline & B-s & 7.4 & $10.9^{\mathrm{i}}$ & 16.1 & 8.2 & 10.2 & 14.3 & 7.8 & 9.7 & 14.4 & 7.4 & 9.1 & 12.3 \\
\hline & B-f & 5.8 & $7.2^{\mathrm{j}}$ & 8.5 & 4.7 & 7.0 & 10.2 & 2.3 & 7.0 & 10.8 & 4.5 & 6.8 & 9.6 \\
\hline & B-fs & 6.0 & $8.8^{\mathrm{h}}$ & 12.6 & 6.1 & 8.7 & 11.3 & 7.0 & 9.6 & 14.0 & 6.4 & 8.4 & 12.4 \\
\hline \multirow{7}{*}{ 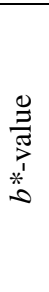 } & A & 13.4 & $14.2^{x}$ & 15.4 & 12.6 & 14.6 & 16.7 & 13.3 & 15.7 & 16.6 & 12.3 & 14.4 & 19.7 \\
\hline & A-f & 11.7 & $14.0^{x}$ & 17.6 & 13.3 & 15.9 & 19.1 & 14.9 & 17.5 & 21.9 & 15.5 & 18.5 & 22.0 \\
\hline & A-fs & 13.1 & $14.5^{x}$ & 16.9 & 15.1 & 17.0 & 20.0 & 13.2 & 17.3 & 20.1 & 16.2 & 18.5 & 22.7 \\
\hline & B & 11.4 & $13.5^{\mathrm{h}}$ & 16.8 & 13.6 & 15.4 & 18.6 & 13.2 & 15.5 & 19.4 & 14.4 & 15.8 & 18.3 \\
\hline & B-s & 11.0 & $13.2^{\mathrm{h}}$ & 16.5 & 10.9 & 13.6 & 16.9 & 11.9 & 13.6 & 14.8 & 12.1 & 13.7 & 16.0 \\
\hline & B-f & 12.0 & $14.4^{\mathrm{h}}$ & 18.5 & 11.0 & 13.5 & 17.6 & 13.4 & 16.6 & 22.7 & 13.1 & 17.5 & 21.6 \\
\hline & B-fs & 14.7 & $16.7^{\mathrm{i}}$ & 20.4 & 14.2 & 16.7 & 20.1 & 15.3 & 17.9 & 21.2 & 16.9 & 18.8 & 24.0 \\
\hline
\end{tabular}

$9 \mathrm{n}=20$ for all measurements.

10 Values for day 1 marked with the same letter (within code A (x, y, z) or B (h, i, j)) are not significantly different. 

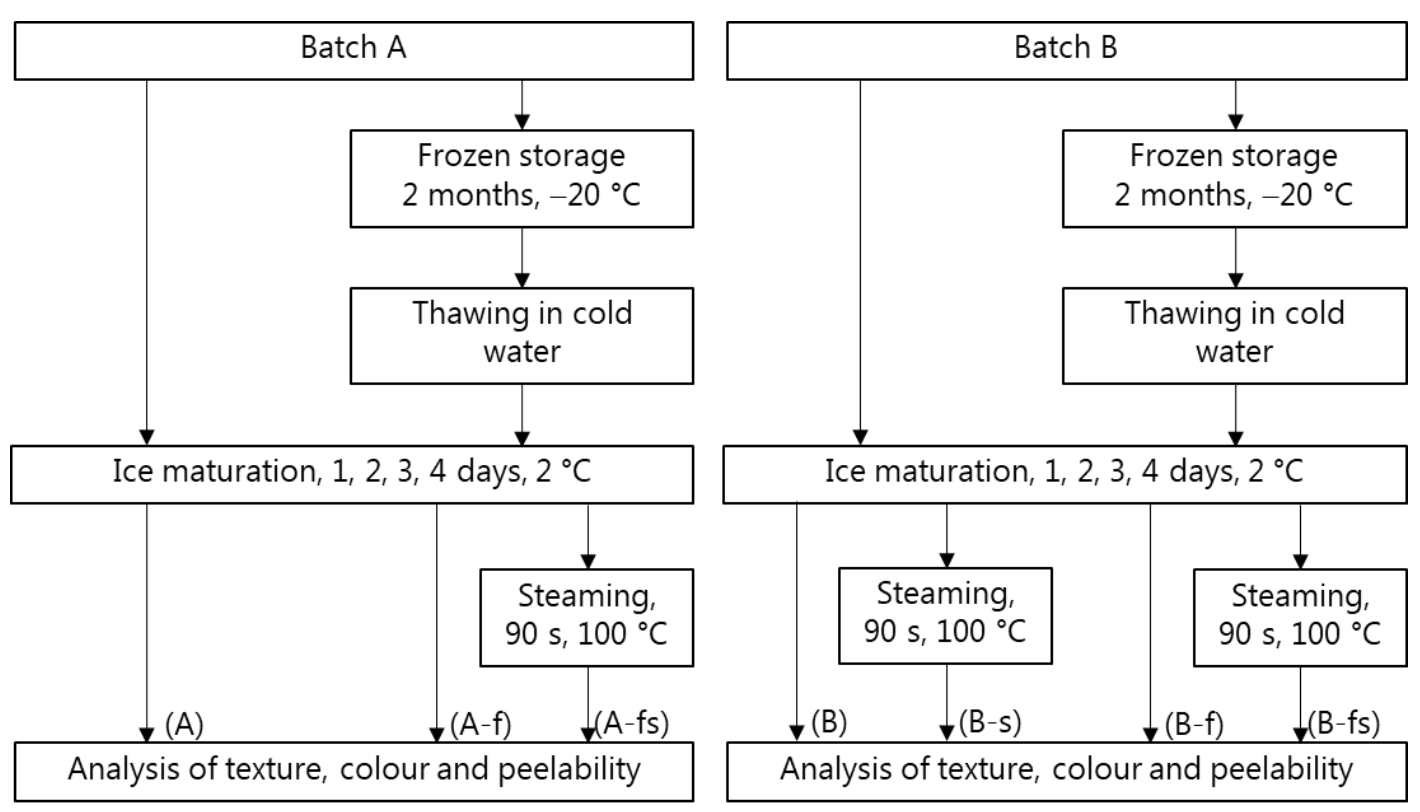

2 Figure 1: Experimental overview. Both batch A and B are analysed as unfrozen and frozen (f) samples

3 as well as uncooked and steamed (s). The unfrozen and steamed shrimps in batch A was not analysed. 


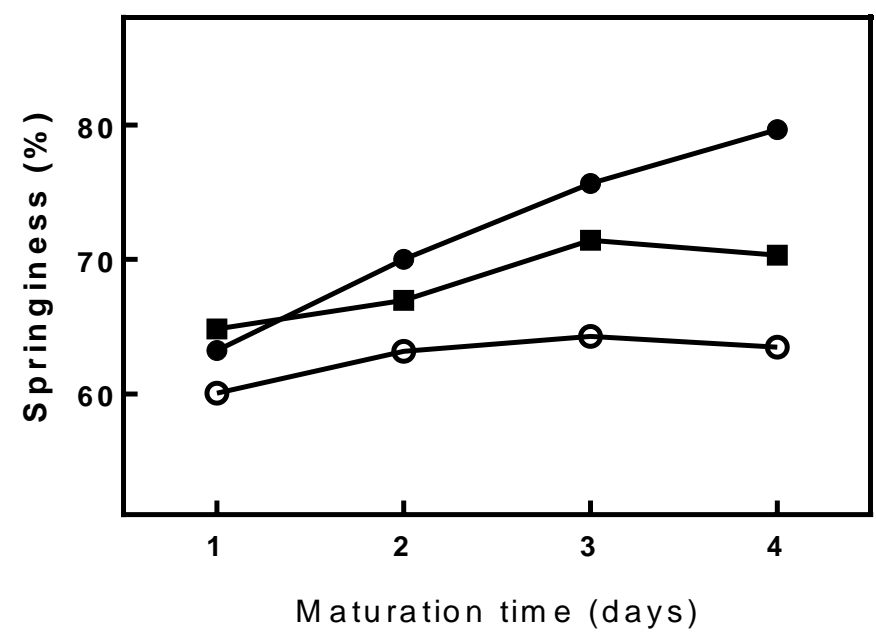

5

6 Figure 2: Effect of maturation time on springiness of steamed shrimps. Unfrozen or frozen/thawed

7 shrimps were matured (stored on ice) for one to four days after which they were steamed and peeled 8 and springiness analysed and shown as the median values. Symbols used: O, unfrozen batch B (B-s); • 9 frozen/thawed batch B (B-fs); $\mathbf{m}$, frozen/thawed batch A (A-fs). 

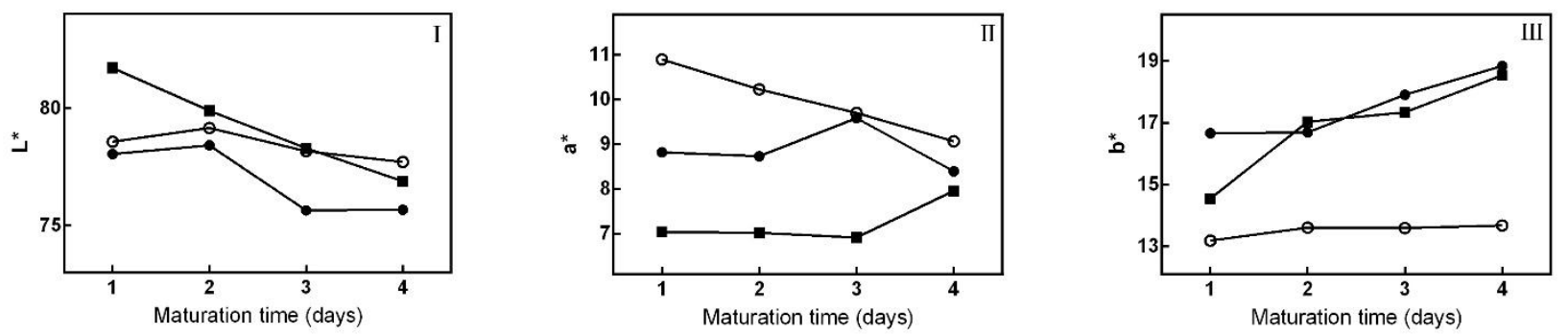

12

13 Figure 3: Effect of maturation time on colour of steamed shrimps. Unfrozen or frozen/thawed shrimps

14 were matured (stored on ice) for one to four days after which they were steamed and their colour

15 parameters $L^{*}$ (Panel I), $a^{*}$ (II) and $b^{*}$ (III) measured and shown as median values. Symbols used: O,

16 unfrozen batch B (B-s); • frozen/thawed batch B (B-fs); $\mathbf{m}$, frozen/thawed batch A (A-fs).

17 


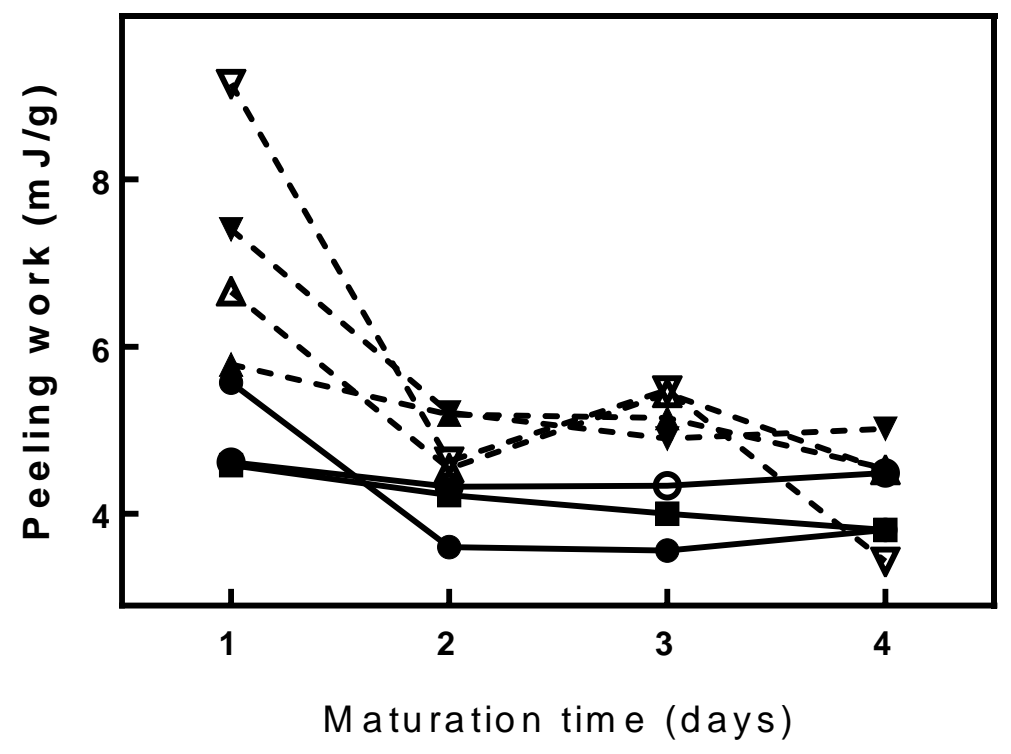

18

19 Figure 4: Effect of maturation time on shrimp peeling work. Unfrozen or frozen/thawed shrimps were 20 matured (stored on ice) for one to four days after which some of them were steamed and some kept 21 uncooked. The peeling work was then measured and results are shown as median values. Symbols used 22 for steamed shrimps (solid lines): O, unfrozen batch B (B-s); • frozen/thawed batch B (B-fs); $\mathbf{m}$, 23 frozen/thawed batch A (A-fs). Symbol used for uncooked shrimps (dashed lines): $\Delta$, unfrozen batch A 24 (A); $\nabla$, unfrozen batch B (B); $\boldsymbol{\Delta}$, frozen/thawed batch A (A-f); $\boldsymbol{\nabla}$, frozen/thawed batch B (B-f). 